\title{
Metabolite secretions of Lactobacillus plantarum YYC-3 may inhibit colon cancer cell metastasis by suppressing the VEGF-MMP2/9 signaling pathway
}

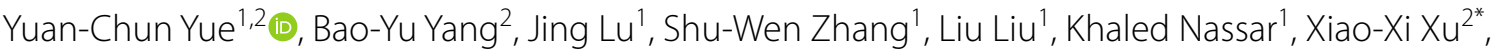 \\ Xiao-Yang Pang ${ }^{1 *}$ and Jia-Ping LV ${ }^{1 *}$
}

\begin{abstract}
Background: Colorectal cancer (CRC) is a major clinical challenge, and the gut microbiome plays important roles in the occurrence and metastasis of CRC. Lactobacillus and their metabolites are thought to be able to suppress the growth of CRC cells. However, the antimetastatic mechanism of Lactobacillus or their metabolites toward CRC cells is not clear. Therefore, the aim of this study was to assess the inhibitory mechanism of cell-free supernatants (CFSs) of $L$. rhamnosus GG, L. casei M3, and L. plantarum YYC-3 on metastasis of CRC cells.

Results: YYC-3 CFS showed the highest inhibitory effect on CRC cell growth, invasion and migration, and inhibited MMP2, MMP9, and VEGFA gene and protein expression, and protein secretion. Furthermore, it suppressed the activities of MMPs by gelatin zymography. Moreover, the effective compounds in these CFSs were analyzed by Q Exactive Focus liquid chromatography-mass spectrometry.

Conclusions: Our results showed that metabolite secretions of YYC-3 may inhibited cell metastasis by downregulating the VEGF/MMPs signaling pathway. These data suggest that treatment of CRC cells with metabolites from $L$. plantarum YYC-3 may reduce colon cancer metastasis.
\end{abstract}

Keywords: Lactobacillus plantarum, Metastasis, Colon cancer cell, VEGFA

\section{Background}

Colorectal cancer (CRC) is a major cause of cancerrelated mortality worldwide, and many patients with CRC are in an advanced stage with distant metastasis [13]. The main inducing factors of colon cancer are genes and the gut environment. The gut microbiome plays a critical role in maintaining the health of the gastrointestinal tract through host-microbe and microbe-microbe

\footnotetext{
*Correspondence: xiaoxi_xu01@163.com; pangxiaoyang@163.com; Ivjiapingcaas@126.com

${ }^{1}$ Institute of Food Science and Technology, Chinese Academy of Agricultural Sciences, Beijing 100193, People's Republic of China ${ }^{2}$ College of Food Science, Northeast Agricultural University, Harbin 150030, People's Republic of China
}

interactions [4-6]. Studies on the impact of the gut microbiota and the effects its metabolite secretions on proliferation and metastasis of colon cancer cells may provide new strategies for treatment of colon cancer. Previous studies have reported that gut microbiota have an effect on the progress of CRC, such as Fusobacterium nucleatum which has a symbiotic relationship with colon cancer and encourages proliferation of colon cancer cells [7].

Lactic acid bacteria (LAB), such as Lactobacillus and Bifidobacterium, are also members of the gut microbiome [8-11]. Some metabolites secreted by LAB exhibit antibacterial properties, for example, bacteriocin; these

(c) The Author(s) 2020. This article is licensed under a Creative Commons Attribution 4.0 International License, which permits use, sharing, adaptation, distribution and reproduction in any medium or format, as long as you give appropriate credit to the original author(s) and the source, provide a link to the Creative Commons licence, and indicate if changes were made. The images or other third party material in this article are included in the article's Creative Commons licence, unless indicated otherwise in a credit line to the material. If material is not included in the article's Creative Commons licence and your intended use is not permitted by statutory regulation or exceeds the permitted use, you will need to obtain permission directly from the copyright holder. To view a copy of this licence, visit http://creativeco mmons.org/licenses/by/4.0/. The Creative Commons Public Domain Dedication waiver (http://creativecommons.org/publicdomain/ zero/1.0/) applies to the data made available in this article, unless otherwise stated in a credit line to the data. 
metabolites may be potent substitutes for antibiotics $[12$, 13].

In recent years, the applications of LAB have extended into the field of cancer prevention, especially for CRC. Previous reports have demonstrated that certain LAB, including Lactobacillus casei, L. paracasei, L. plantarum, and $L$. reuteri, can inhibit the growth of cancer cells [14-16]. The anti-cancer mechanisms attributed to these LABs include promoting apoptosis of the cancer cells through intrinsic and extrinsic apoptotic pathways, anti-proliferative regulation of the cell cycle in cancer cell lines, sequestering of reactive oxygen species by antioxidative enzymes to prevent carcinogenesis, production of bacterial enzymes, effecting the metabolites and epigenetics of the host, and regulating different signalling pathways in colon cancer cells $[17,18]$.

Vascular endothelial growth factor (VEGF)-MMPs is one of the most important signalling pathways and is involved in multiple cellular processes, including cell migration, invasion, and vascular cell permeability [19]. VEGF is considered the major endothelial mitogen in the neoplasms of the central nervous system [20]. In some tumours, the expression of VEGFA is associated with angiogenesis and metastasis, which are processes involved in the invasion of cancer cells using the extracellular matrix (ECM). In the VEGF-MMPs signalling pathway, VEGF binds to its receptor, VEGFR, which is associated with the secretion of the downstream target, matrix metalloproteinases (MMPs). MMPs are calciumdependent and zinc-containing endopeptidases that can be induced by an autocrine VEGF/VEGFR signalling pathway loop [21]. It had been reported that cancer cells use MMPs to degrade ECM during invasion and metastasis [22].

Previously, we identified L. rhamnosus GG, L. casei M3 and L. plantarum YYC-3 from 120 strains of LAB by the high antibacterial activities of their cell free supernatants
(CFSs) using the cup-plate method on F. nucleatum, which is the symbiotic strain involved in colon cancer (not published). We found that L. plantarum YYC-3 modulated the tumour microenvironment to prevent colon cancer in $A P C^{\mathrm{Min} /+}$ model mice [23]. However, the direct effects of L. plantarum YYC-3 CFS on human colon cancer cell metastasis remains unclear.

Therefore, the aim of this study was to investigate the inhibitory effects of the metabolite secretions of L. rhamnosus GG, L. casei M3 and L. plantarum YYC-3 on colon cancer cell metastasis, and to determine their molecular mechanisms using the human colorectal carcinoma cell lines Caco-2 and HT-29.

\section{Results}

Cytotoxicity of colon cancer cells treated with cell free supernatants from Lactobacillus

To explore the effect of Lactobacillus CFS on colon cancer cytotoxicity (Table 1 ), the CCK- 8 method was used. In both the Caco- 2 and HT-29 cells, an increasing concentration of Lactobacillus CFS resulted in enhanced cytotoxicity. At a concentration of $800 \mu \mathrm{L} / \mathrm{mL}$, the cell viability was inhibited the most effectively (as high as $100 \%$ ) in Caco-2 cells treated with CFS of M3 (Table 1). The half maximal inhibitory concentration $\left(\mathrm{IC}_{50}\right)$ values of all the treatment groups (GG, M3, and YYC-3) were $344.81,291.66$, and $312.78 \mu \mathrm{L} / \mathrm{mL}$, respectively. Similarly, the growth of the HT-29 cells were also inhibited in a dose-dependent manner after treatment with CFSs of GG, M3, and YYC-3, the $\mathrm{IC}_{50}$ values of these were 358.21, 349.88 , and $259.91 \mu \mathrm{L} / \mathrm{mL}$, respectively. Their inhibitory rates were comparable to those of $2.5 \mu \mathrm{M} 5$-flourouracil (5-FU, positive control) which could inhibit approximately $50 \%$ of the HT- 29 cells. Treatment with MRS medium showed no significant reduction in the viability of the Caco-2 and HT-29 cells. These results indicate

Table 1 The IC ${ }_{50}$ value $(\mu \mathrm{L} / \mathrm{mL})$ by CFSs of LAB on Caco- 2 and HT-29 cells

\begin{tabular}{|c|c|c|c|c|c|c|c|c|c|c|}
\hline \multicolumn{11}{|c|}{ Concentration $(\mu \mathrm{L} / \mathrm{mL})$} \\
\hline Cell lines & Strains & 80 & 100 & 200 & 300 & 400 & 500 & 600 & 700 & $I C_{50}$ value \\
\hline \multirow[t]{4}{*}{ Caco-2 } & $\mathrm{GG}$ & - & $1.63 \pm 0.03$ & $22.83 \pm 0.19$ & $40.28 \pm 0.13$ & $53.76 \pm 0.04$ & $61.62 \pm 0.08$ & $84.53 \pm 0.15$ & $92.22 \pm 0.06$ & $344.81 \pm 0.08$ \\
\hline & M3 & - & $7.28 \pm 0.06$ & $27.52 \pm 0.13$ & $51.16 \pm 0.09$ & $68.30 \pm 0.12$ & $72.83 \pm 0.04$ & $89.32 \pm 0.11$ & $96.48 \pm 0.13$ & $291.66 \pm 0.13$ \\
\hline & YYC-3 & - & $5.27 \pm 0.01$ & $26.39 \pm 0.06$ & $48.23 \pm 0.16$ & $60.27 \pm 0.08$ & $69.44 \pm 0.11$ & $88.10 \pm 0.13$ & $94.72 \pm 0.09$ & $312.78 \pm 0.06$ \\
\hline & MRS & - & - & - & - & - & - & - & $0.02 \pm 0.001$ & - \\
\hline \multirow[t]{4}{*}{ HT-29 } & GG & - & $3.41 \pm 0.03$ & $12.75 \pm 0.22$ & $39.47 \pm 0.12$ & $50.11 \pm 0.16$ & $73.59 \pm 0.13$ & $82.93 \pm 0.09$ & $95.37 \pm 0.12$ & $358.21 \pm 0.08$ \\
\hline & M3 & - & $3.16 \pm 0.01$ & $10.73 \pm 0.08$ & $43.21 \pm 0.12$ & $50.09 \pm 0.11$ & $75.28 \pm 0.18$ & $86.81 \pm 0.11$ & $92.42 \pm 0.17$ & $349.88 \pm 0.21$ \\
\hline & YYC-3 & - & $9.77 \pm 0.01$ & $30.69 \pm 0.10$ & $63.73 \pm 0.08$ & $72.71 \pm 0.13$ & $80.10 \pm 0.02$ & $89.73 \pm 0.07$ & $93.58 \pm 0.06$ & $259.91 \pm 0.10$ \\
\hline & MRS & - & - & - & - & - & - & - & - & - \\
\hline
\end{tabular}


Table 2 Primer sequences

\begin{tabular}{|c|c|c|c|}
\hline Gene name & Forward primer $\left(5^{\prime}-3^{\prime}\right)$ & Reverse primer $\left(5^{\prime}-3^{\prime}\right)$ & $\begin{array}{l}\text { Product } \\
\text { size (bp) }\end{array}$ \\
\hline MMP2 & AATGCCATCCCCGATAACCT & CACGCTCTTCAGACTTTGGTTC & 114 \\
\hline MMP9 & GAGCACGGAGACGGGTATC & ACTCGTCATCGTCGAAATGG & 106 \\
\hline VEGF-A & CAGATTATGCGGATCAAACCTCACC & CACAGGGAACGCTCCAGGACTTAT & 190 \\
\hline GAPDH & CACCCACTCCTCCACCTTTGA & TCTCTCTTCCTCTTGTGCTCTTGC & 188 \\
\hline
\end{tabular}

that the CFSs of YYC-3 has the highest cytotoxicity effect among the three LABs on colon cancer cells.

\section{Analysis of cell invasion and cell migration}

To analyse the effect of Lactobacillus CFS on colon cancer cell metastasis, the invasion and migration of colon cancer cells was evaluated with Transwell $^{\mathrm{TM}}$ assays. These results are shown in Fig. 1, treatment with CFS limited the ability of the Caco-2 and HT-29 cells to traverse and invade the filter membranes as shown in Fig. 1a, b, and suppressed cell migration (Fig. 1c, d, $P<0.05$ ). For Caco-2 cells, treatment with the CFS of YYC-3 showed the highest inhibition of cell invasion. Compared with the negative control ( $90 \pm 4.3$ cells), only $40 \%$ of cells $(36 \pm 2.1$ cells) in the treated group of YYC-3 traversed through the filter membranes, which was significantly fewer than the control $(P<0.05)$. The migration of Caco- 2 cells was also significantly inhibited with the treatment of the CFS of YYC-3, with only $34 \%$ of cells ( $56 \pm 1.8$ cells) traversing through the filter membranes (data in Fig. 1 and the images shown in Additional file 1: Figure S1). Moreover, the other two groups also exhibited significantly limited cellular invasion and migration. Among the three treatment groups of CFS, the cells with YYC-3 showed the highest ability to inhibit the invasion and migration of Caco-2 and HT-29 cells.

\section{Analysis of the effective compounds in the CFS}

To identify the potential effective compounds by which CFSs affect colon cancer cell metastasis, Q Exactive Focus liquid chromatography-mass spectrometry was used to analyse the metabolites in these LABs. Figure 2 shows the four identified effective compounds, which included oleic acid, cytidine, oleanolic acid, and yohimbine. The molecular weights in the database were 522.36, $243.09,456.36$, and 354.19 , respectively. The production of these four compounds was highest in the YYC-3 strain, followed by GG then M3. Compared with the other three compounds, the output of oleic acid was the highest. These results indicate that oleic acid, cytidine, oleanolic acid, and yohimbine are the potential effective compounds in the CFSs that inhibit colon cancer cell metastasis.

\section{Analysis of gene expression}

In view of the mechanism by which these identified compounds in the CFSs exert their effect on cancer cell metastasis, by inhibiting VEGF. We further verified the effective compounds, by analysing the key genes $M M P 2, M M P 9$, and VEGFA in the VEGF-MMPs signalling pathway of colon cancer cells using real-time (RT)PCR (Fig. 3). Compared with the negative control, the expression of $M M P 2, M M P 9$, and VEGFA were significantly decreased in all the CFS-treated groups. In Caco-2 cells, the YYC-3 treated group had significantly reduced $M M P 2, M M P 9$, and VEGFA gene expressions that were $0.30,0.25$, and 0.30 fold of the negative control group, respectively. The other two treatment groups also had reduced $M M P 2, M M P 9$, and VEGFA gene expression. In HT-29 cells, these three gene expressions were significantly reduced in the $\mathrm{YYC}-3$ treated groups compared with the negative control group $(\sim 0.32$ fold). Moreover, treatment with YYC-3 CFS resulted in the largest reduction of these gene expressions, about 0.3-fold compared with the negative control group.

\section{Analysis of protein levels}

Western blots were used to survey the inhibitory ability of Lactobacillus CFS on the protein levels of MMP2, MMP9, and VEGFA in colon cancer cells. Treatment with YYC-3 resulted in the greatest inhibition of MMP2, MMP9, and VEGFA protein levels in both the Caco-2 and HT-29 cells. Moreover, treatment with M3 CFS repressed MMP2 and VEGF protein levels in Caco-2 cells, but did not induce a significant reduction $(\mathrm{P}>0.05)$ in MMP9 protein levels (Fig. 4a). Treatment of HT-29 cells with M3 CFS, however, did result in a significant decrease in the levels of MMP2, MMP9, and VEGFA (Fig. 4b).

\section{Assessment of protein secretion}

VEGF-MMPs are involved in the degradation of essentially all extracellular matrix (ECM) components but they must be secreted into the extracellular matrix for 


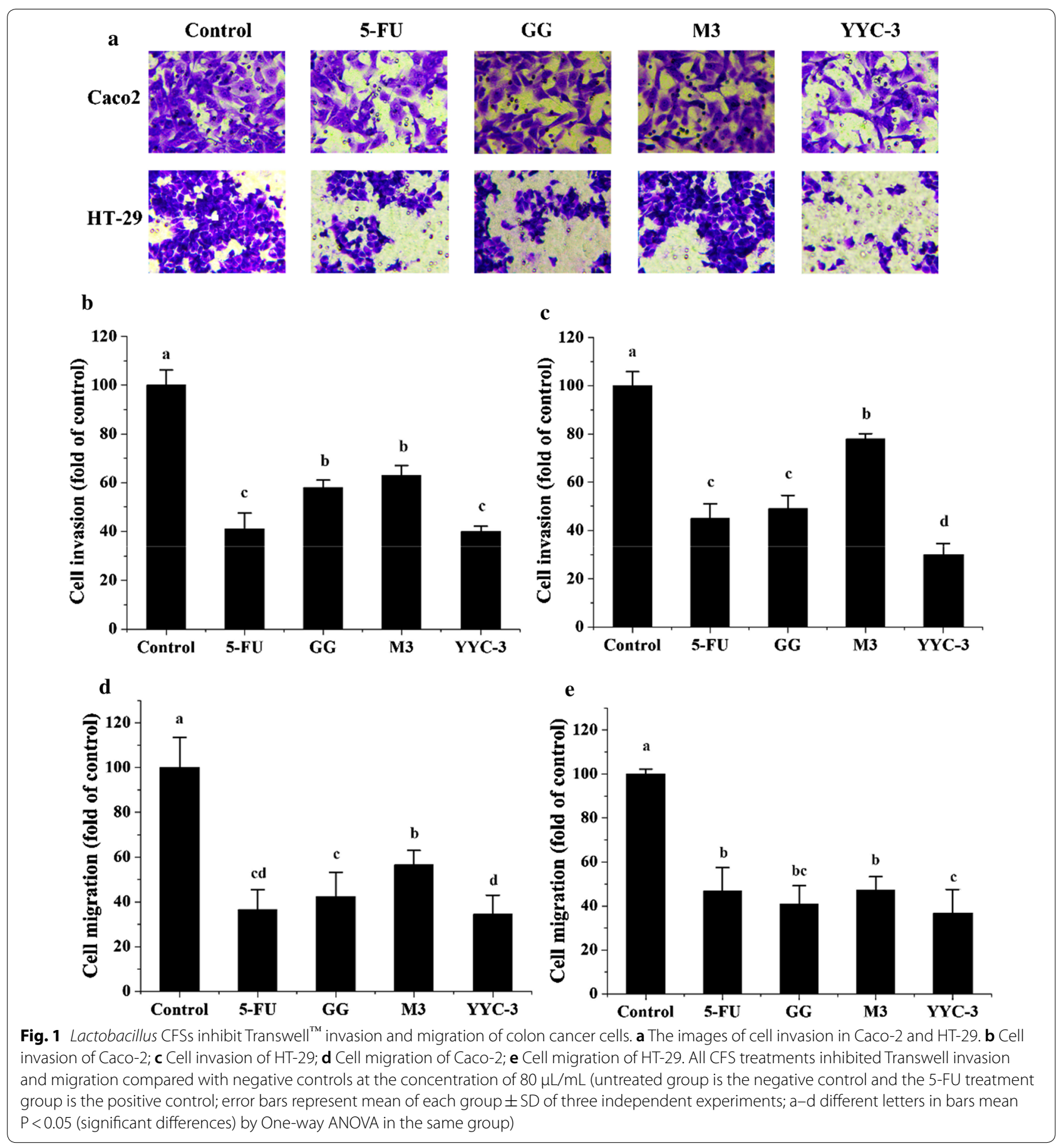

this action. Thus, the level of secreted VEGF-MMPs proteins were determined. The secretion of MMP2, MMP9, and VEGFA proteins in the YYC-3 treated group were less than those of the other groups (Fig. 5a, b). The treatment of Caco2 cell with YYC-3 CFS showed that MMP2, MMP9, and VEGFA (360.8, 96.9, and $326.4 \mathrm{pg} / \mathrm{mL}$, respectively) were significantly lower than the untreated group $(P<0.001)$. However, in HT-29 cell, YYC-3 CFS treatment resulted in a protein secretion level of 406.1, 109.5 , and $367.5 \mathrm{pg} / \mathrm{mL}$ in these proteins, respectively, which was also significantly lower than the untreated group $(P<0.001)$. Furthermore, when the YYC-3 treated group was compared with the positive control (5-FU), there was a significant difference $(P<0.05)$ in the MMP2 

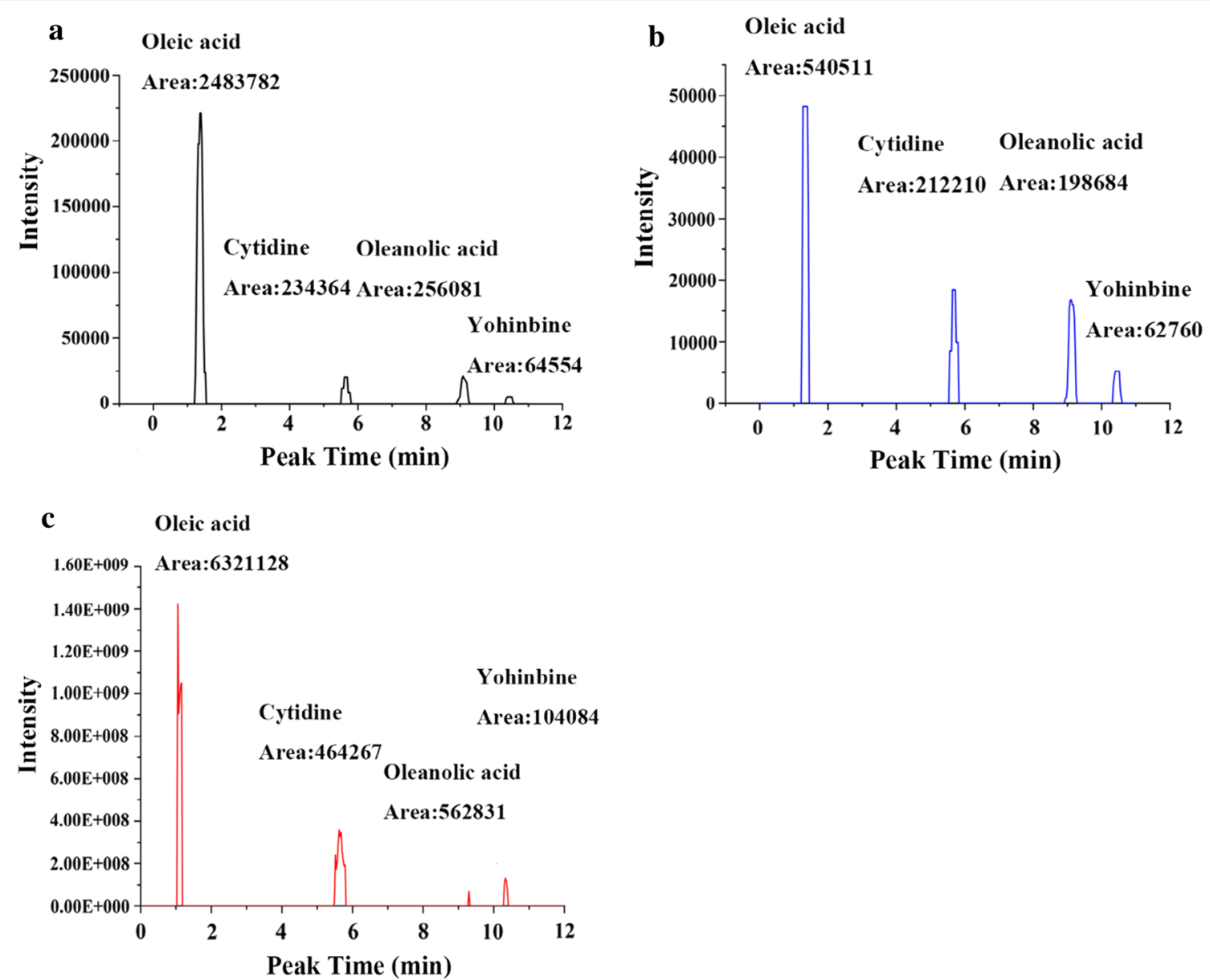

Fig. 2 Inhibitory effect of CFSs on cell growth and effective compound analysis of CFSs. a Cell growth of Caco-2; b Cell growth of HT-29; c Effective compound analysis of YYC-3 CFSs. Using the method of CCK-8, and $10 \%(\mathrm{~V} / \mathrm{V})$ CFSs were added in the treated groups and cultured for 24,48 , and $72 \mathrm{~h}$, respectively. And (UPLC)-Q Exactive Focus-MS/MS was used for evaluated effective compounds. Treatment groups and positive control were compared with the negative control, and ${ }^{*}$ means $P<0.05,{ }^{* *}$ means $P<0.01$, ***means $P<0.001$

and VEGFA protein secretion levels; although no significant differences $(P>0.05)$ was observed in the MMP9 was observed in both the Caco2 and HT-29 cells.

\section{MMP2 and MMP9 activities by gelatine zymography}

To test the inhibitory ability of Lactobacillus CFSs on the activity of MMP-2 and MMP-9. The activities of MMP2 and MMP9 were evaluated using gelatine zymography. The results are shown in Fig. 5c, d. All the treatment groups showed significant inhibition of MMP2 and MMP9 activity in both the Caco2 and HT-29 cells (Fig. $5 \mathrm{c}, P<0.05$ ). Among them, the YYC-3 treated group showed the highest ability to suppress MMP2 and MMP9 activities, which decreased to $19.1 \pm 2.9 \%$ (MMP2) and $30.3 \pm 1.4 \%$ (MMP9) compared to the control in Caco2 cells, respectively. Moreover, for HT-29 cells, YYC-3 downregulated MMP2 and MMP9 activity to $14.2 \pm 4.7 \%$
(MMP2) and $11.5 \pm 3.1 \%$ (MMP9) compared to the control, respectively.

\section{Discussion}

LAB are probiotic microorganisms that have been implicated as anticancer agents, and may inhibit colon cancer cells through direct interactions and/or via the secretion of bacteriocin and other bioactive components [2426]. P8 protein that produced by $L$. rhamnosus KCTC 12202BP, shows strong inhibitory effect on colon cancer cell by inducing cell cycle arrest [27]. And Lee et al. evidenced the anti-cancer activity of the probiotic bacterium L. fermentum using 3D culture in colon cancer cells [28]. Moreover, Carmen et al. revealed LAB shows anti-cancer effect by expressing antioxidant enzymes or IL-10 in colon cancer model mice [29]. However, only a few reports have focused on the effects of $L A B$ and their 


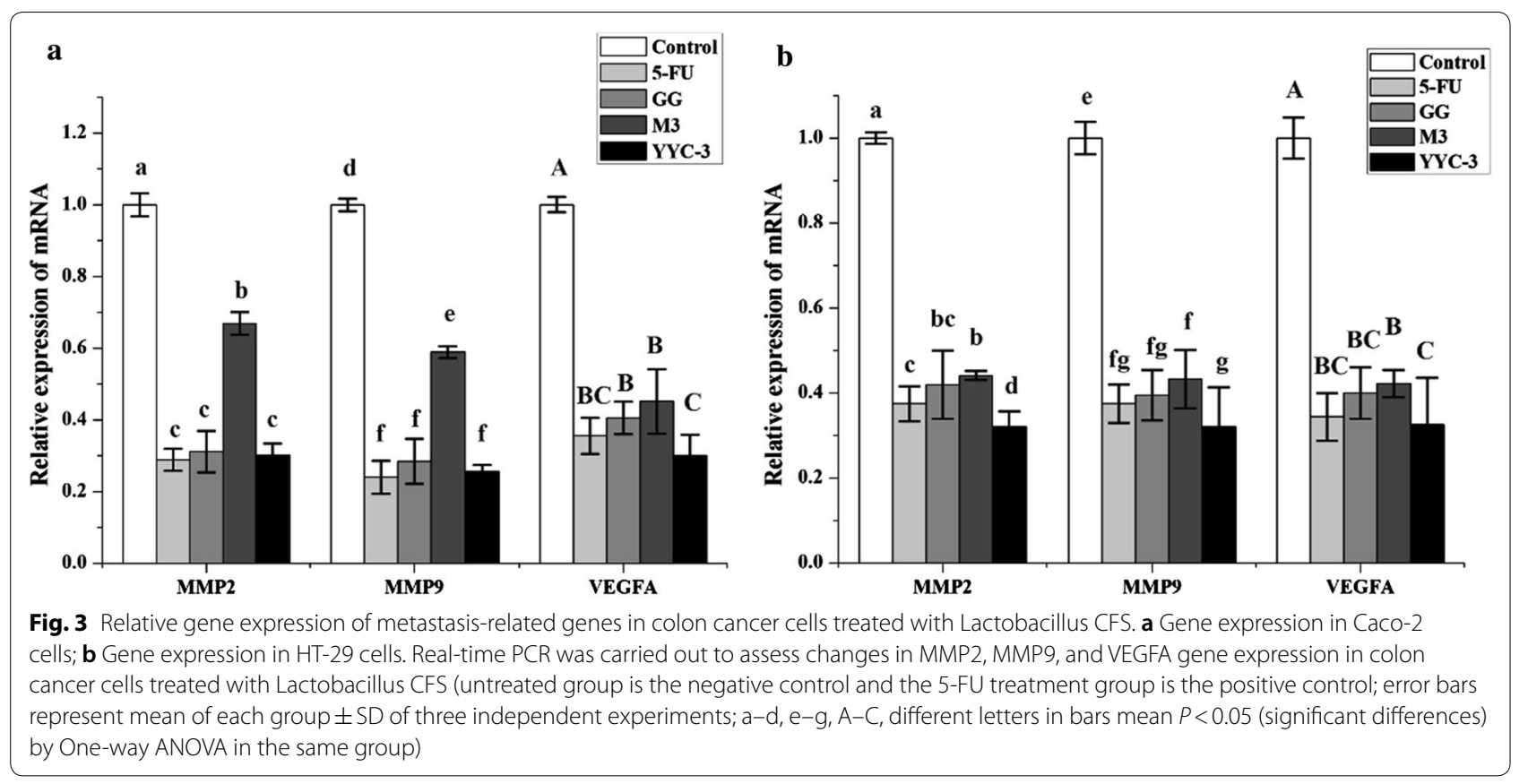

a
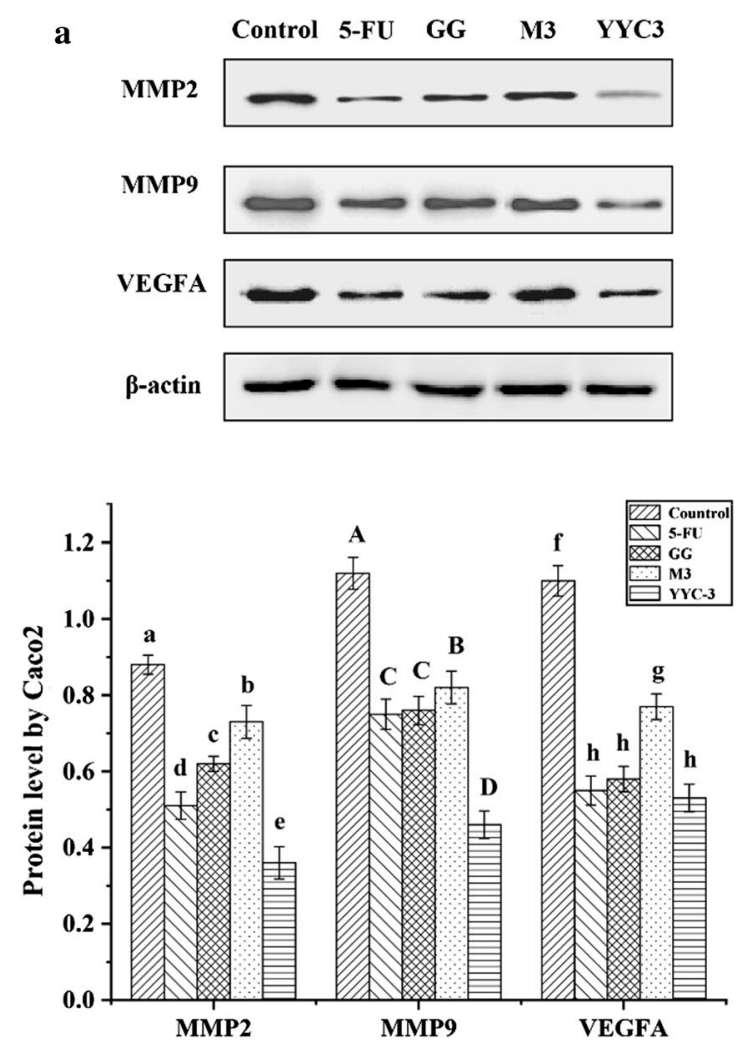

b

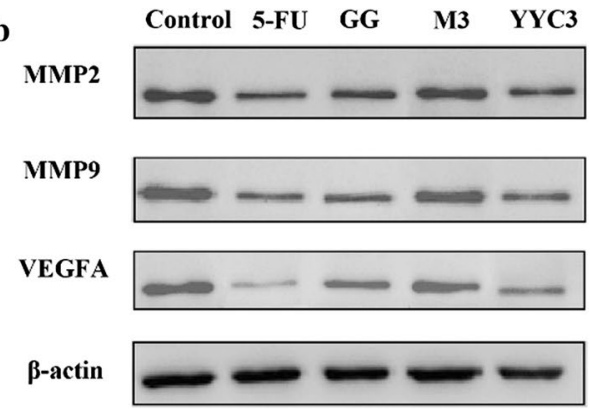

Fig. 4 Relative protein level from metastasis-related genes in colon cancer cells treated with Lactobacillus CFS. a Protein level of Caco-2; b Protein level of HT-29. Western blot analysis was performed to determine changes in protein level of MMP2, MMP9, and VEGFA in colon cancer cells treated with Lactobacillus CFS (untreated group is the negative control and the 5-FU treatment group is the positive control; error bars represent mean of each group $\pm S D$ of three independent experiments; $a-e, A-D, f-i$, different letters in bars mean $P<0.05$ (significant differences) by One-way ANOVA in the same group) 

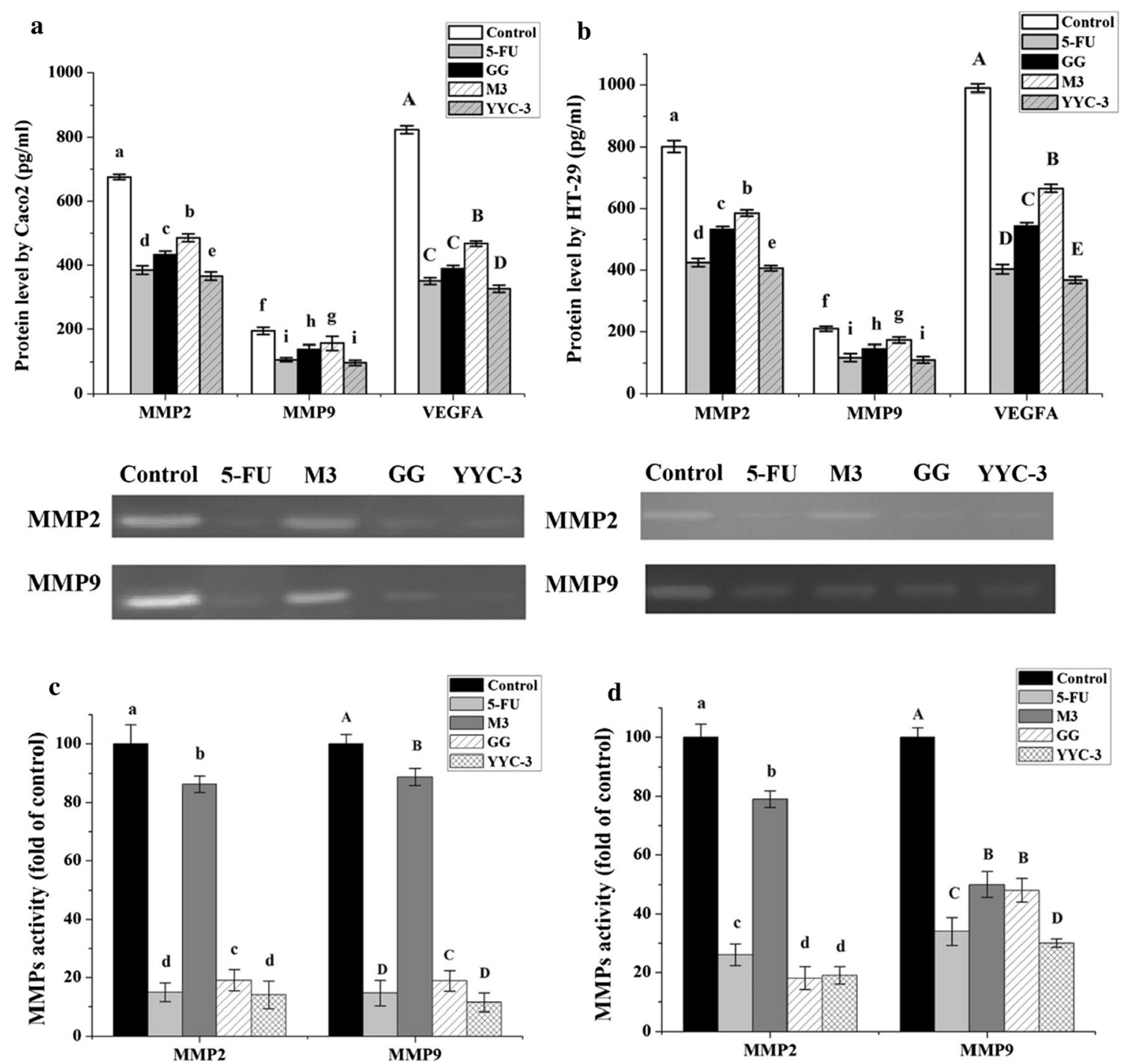

Fig. 5 Protein secretion of MMP2, MMP9, and VEGFA and activity of MMPs by colon cancer cells treated with Lactobacillus CFS. a Caco-2 protein secretion; b HT-29 protein secretion; c Caco-2 MMPs activity. $\mathbf{d}$ HT-29 MMPs activity. ELISA analysis was performed to determine changes in protein secretion of MMP2, MMP9, and VEGFA and gelatin zymography was used to test the activity of MMPs in colon cancer cells treated with Lactobacillus CFS (untreated group is the negative control and the 5-FU treatment group is the positive control; error bars represent mean of each group \pm SD of three independent experiments; $a-e, f-i, A-E$, different letters in bars mean $P<0.05$ (significant differences) by One-way ANOVA in the same group

metabolites on colon cancer cell metastasis. In this study, we used the metabolites of three LAB (L. rhamnosus GG, L. casei $\mathrm{M} 3$ and $L$. plantarum $\mathrm{YYC}-3$ ) to explore their anticancer effects and the related molecular mechanisms on colon cancer cell lines (Caco-2 and HT-29). We found that the metabolites of these LABs could suppress the metastasis of colon cancer cells by inhibiting the VEGF/ MMPs signalling pathway, which demonstrated the anticancer function of these $\mathrm{LAB}$.

LAB and its metabolite secretions have been evidenced to be cytotoxic to colon cancer cells. Faghfoori et al. demonstrated that L. plantarum had a cytotoxic effect on HT-29 cells [30]. Our results showed that the CFS of YYC-3 had the highest inhibitory activity toward HT-29 cell, with an $\mathrm{IC}_{50}$ value of $259.91 \pm 0.10 \mu \mathrm{L} / \mathrm{mL}$. Similarly to the results of Chen et al. [31], who also found that L. plantarum PM153 exhibited an anticancer effect on HT-29 cell $\left(\mathrm{IC}_{50}\right.$ value was $\left.299.3 \mu \mathrm{L} / \mathrm{mL}\right)$ under similar conditions. However, Vemuri et al. [32] found that L. plantarum UALp-05 did not significantly influence on HT-29 cells. These results suggest that the inhibitory activity by $L$. plantarum may be strain-specific.

Cancer-associated mortality is mainly associated with metastasis from the primary tumour to distant organs, 
such as lung, liver, and brain [33]. For the anti-metastasis of LAB on colon cancer cells, Escamilla et al. [34] reported that the CFSs of $L$. casei and L. rhamnosus GG had inhibitory effects on the invasion of HCT-116 colon cancer cells. They also reported that the CFS of L. casei showed a higher inhibitory effect on the cell invasion than that of L. rhamnosus GG. In this study, we also demonstrated the inhibitory effect of CFSs by $L$. casei and L. rhamnosus GG on colon cancer cell invasion and migration using Caco-2 and HT-29 cells. Contrary to the report of Escamilla et al., we found that CFS of $L$. casei M3 had a lower inhibitory effect on colon cancer cell metastasis when compared with that of $L$. rhamnosus GG. The variations of our report with that of Escamilla et al. could be strain-dependent or due to cell line differentiation.

In this study, all treatment groups had significant inhibitory effects on Caco2 and HT-29 cell invasion and migration. However, the YYC-3-treated group showed the highest ability to inhibit the invasion and migration of the cells, when compared with the other treatment groups. Therefore, it could be inferred that the CFS of YYC-3 may have the most effective compounds compared to the other two stains.

There are many reports on the inhibitory effect of natural products in tumour metastasis. To evaluate the specific compounds implicated in the inhibitory activity, the CFSs of the three strains were analysed using Q Exactive Focus liquid chromatography-mass spectrometry, and oleic acid, oleanolic acid, yohimbine and cytidine were identified in all three CFSs. The concentrations of these substances positively correlated with the anticancer activity demonstrated by the strains. Interestingly, several reports have proven that oleic acid, oleanolic acid, yohimbine and cytidine possess anticancer activity by the suppressing tumour metastasis [35-38]. Furthermore, natural products containing these compounds have been reported to inhibit the expression of VEGF. This is an angiogenic factor, and is closely related to organ development, endothelial cell growth, and blood vessel permeability [39]. VEGFA also facilitates the invasion of cancer cells via the VEGFA/ VEGFAR pathway by activating p38 mitogen-activated protein kinase MAPK and phosphatidylkinase B (AKT) in order to induce MMP expression, which are widely used to indicate the metastatic capability of colon cancer cells [21]. MMP2 and MMP9 are gelatinases that are able to degrade and remodel ECM [20]; for these reasons MMP2 and MMP9 play important roles in promoting the metastasis of tumour cells. Furthermore, the effect of CFSs from LAB on gene expression, protein levels and protein secretion in the colon cancer cell experiments have verified this molecular mechanism, which is the inhibition of the VEGF-MMP2/9 pathway and evidence the effective compounds of oleic acid, oleanolic acid, yohimbine and cytidine.

The inhibition of MMP2 and MMP9 could suppress the metastasis of cancer cells. The CFSs of L. rhamnosus GG and L. crispatus have been reported to downregulate MMP2 and MMP9 in HT-29 and HeLa cells, thus indicating anti-metastasis [40]. Moreover, Norouzi et al. [41] reported that nisin, as the product of Streptococcus lactate, could attenuates the expression of the metastatic genes MMP2 and CEA inhibiting colon cancer cell metastasis. In this study, we demonstrated that the metabolite secretions of GG, M3 and YYC-3 suppressed VEGFA expression and secretion, and limited the expression and secretion levels of MMP2 and MMP9; suggesting that the inhibition of VEGF-MMP signalling pathway is suppressing cancer cell metastasis. Similarly, the YYC-3 treatment group exhibited the highest inhibitory activity on the target gene protein levels and secretions in Caco-2 and HT-29 cells. These results further validated the highest inhibitory activity demonstrated on cell invasion and migration of Caco-2 and HT-29 cells by YYC-3. However, Escamilla et al. [34] showed that the CFS of B. thetaiotaomicron did not inhibit colon cancer cell invasion.

The pathway by which the CFSs of YYC-3, M3 and GG inhibit colon cancer cell metastasis are modelled in Fig. 6. The pathway indicated that these CFSs inhibited the expression of VEGFA, thereby limiting the VEGFA/ VEGFAR pathway. It also showed that the expression of MMP2 and MMP9 were suppressed, which resulted in the inhibition of colon cancer metastasis.

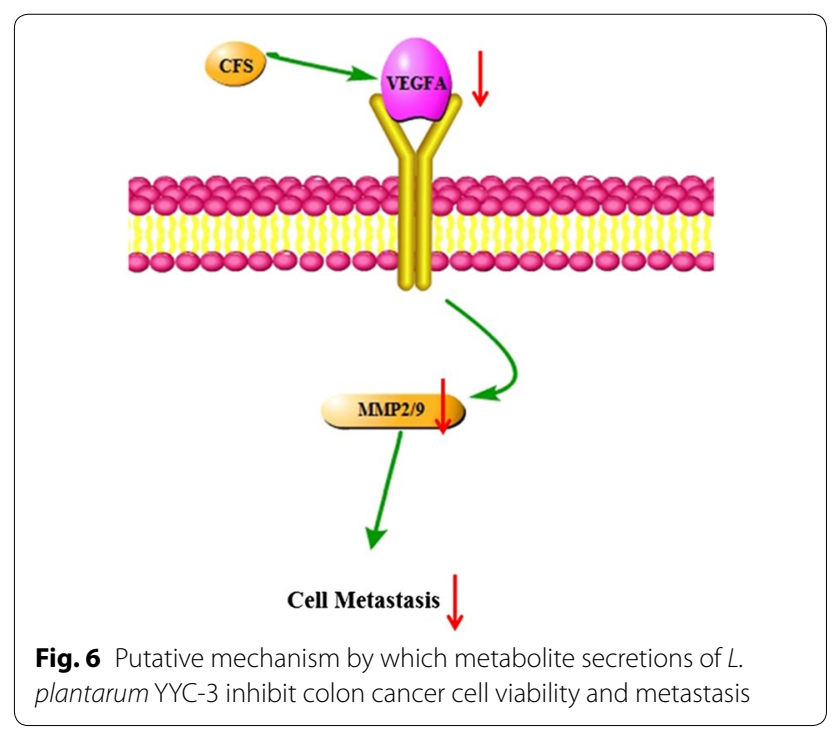




\section{Conclusion}

In this paper, we demonstrate the inhibition of cell growth and antimetastatic activities of the metabolite secretions of L. rhamnosus GG, L. casei M3, and $L$. plantarum YYC-3 toward colon cancer cell lines. The inhibitory activities of these CFSs were as effective as that of a conventional chemotherapy drug (5-FU). Among these Lactobacillus strains, L. plantarum YYC-3 showed the best inhibitory activities against the metastasis of colon cancer cells. These CFSs suppress VEGFA expression, and may exert their anticancer activities through repression of MMP2 and MMP9 downstream of the VEGFA/VEGFAR pathway. This study demonstrates that these three Lactobacillus strains may have potential as alternatives to conventional drugs for the treatment of colon cancer. Further research is required to explore the effects of these probiotic bacteria on colon cancer cells, as well as to assess the inhibitory activities of these bacterial cells and their supernatants in vivo.

\section{Methods}

\section{Cell lines and culture conditions}

Human colon cancer cell lines (HT-29 and Caco-2) were purchased from Procell Life Science \& Technology Co., Ltd., China. HT-29 cell was cultured in Dulbecco's modified Eagle's medium (DMEM)/high glucose medium (Procell Life Science \& Technology Co., Ltd.) supplemented with $10 \%$ foetal bovine serum (FBS) and Caco2 cell was cultured in minimum Eagle's medium (MEM) with $20 \%$ FBS, both of them contains $1 \%$ penicillin $(100 \mathrm{IU} / \mathrm{mL})$ and streptomycin $(100 \mu \mathrm{g} / \mathrm{mL})$ in sterile conditions at $37^{\circ} \mathrm{C}$ in a humidified atmosphere with $5 \% \mathrm{CO}_{2}$. The culture medium was replaced every 2 days.

\section{Bacterial culture and preparation of cell-free supernatant} Lactobacillus rhamnosus GG and L. casei M3 were obtained from the Institute of Food Science and Technology, Chinese Academy of Agricultural Sciences (CAAS), Beijing, China. L. plantarum YYC-3 was isolated from fermented rose juice, as previously described [23]. All the strains obtained were cultured using 5\% inoculum size in $100 \mathrm{~mL}$ MRS broth, and then incubated anaerobically in an anaerobic jar (UNITECH, UT706, China) together with GENbag anaer (AnaeroGen, Oxoid) at $37{ }^{\circ} \mathrm{C}$ without shaking for $24 \mathrm{~h}$. Thereafter, $1 \mathrm{~mL}$ of these cultures, containing about $10^{9}$ colony-forming units $/ \mathrm{mL}$ of $\mathrm{LAB}$, was centrifuged at $6010 \times g$ for $10 \mathrm{~min}$ and the supernatants were retained. The $\mathrm{pH}$ of the supernatants was adjusted to 7.2 using $1 \mathrm{M} \mathrm{NaOH}$, and then the supernatants were passed through $0.22 \mu \mathrm{m}$ filters (Sartorius Stedim Biotech). The filtrates obtained were used for analysis. $2.5 \mu \mathrm{M}$ (Selleck, USA) of 5-FU was used as positive control in this manuscript.

\section{Analysis of cytotoxicity}

Cell Counting Kit-8 (CCK-8) (Solarbio, China) assays were used to evaluate the cytotoxic impact of Lactobacillus CFS on CRC cells. Briefly, $5 \times 10^{4}$ CRC cells were seeded into each well of a 96-well plate in $100 \mu \mathrm{L}$ complete medium. Cells were incubated overnight in normal cell growth conditions to enable cells to adhere to the wells. Next, the medium in each well was replaced, and different concentrations of Lactobacillus CFS (20, $30,40,50,60,70,80$, and $100 \%$ CFS, diluted with complete medium) were added and cultured for $24 \mathrm{~h}$ to test cytotoxicity effect and measure the $\mathrm{IC}_{50}$ value. Next, 10 $\mu \mathrm{L}$ of CCK- 8 solution was added to each well and the plates were incubated at $37^{\circ} \mathrm{C}$ for an additional $4 \mathrm{~h}$, and, $100 \mu \mathrm{L}$ complete medium were used as negative controls; $2.5 \mu \mathrm{M}$ 5-FU was used as a positive control for cytotoxicity. After $24 \mathrm{~h}$ incubation, $10 \mu \mathrm{L}$ of CCK-8 solution were added to each well and the plates were incubated at $37{ }^{\circ} \mathrm{C}$ for an additional $4 \mathrm{~h}$. Cytotoxicity effect was measured using a spectrophotometer (TECAN, Spark $20 \mathrm{M}$, Switzerland) at $450 \mathrm{~nm}$. Inhibition ratio $(\%)=\left[\left(\mathrm{OD}_{\text {untreated }}-\mathrm{OD}_{\text {treated }}\right) /\left(\mathrm{OD}_{\text {untreated }}\right)\right] \times 100 \%$. The analysis was performed in triplicate. The $\mathrm{IC}_{50}$ value was estimated by inhibitory rates and calculated using Logit of probit regression in SPSS19.0.

\section{Analysis of the chemical composition of CFS}

CFSs were centrifuged using ultrafiltration devices (1 kDa cut-off, PALL Corporation) at $650 \times g$ for $50 \mathrm{~min}$ at $4{ }^{\circ} \mathrm{C}$. Then, the compounds of the CFSs that $<1 \mathrm{kDa}$ were analysed by ultra-performance liquid chromatography (UPLC)-Q Exactive Focus-MS/MS (Thermo Scientific Co. Ltd). A C18 column $(2.1 \times 100 \mathrm{~mm}, 1.8 \mu \mathrm{m})$ was used in UPLC with $0.1 \% \mathrm{HCOOH}(\mathrm{A})$ and acetonitrile (B) as mobile phase. The flow rate was as $0.3 \mathrm{~mL} / \mathrm{min}$, and the gradient was: A/B 95/5 (0 min), 10/90 (15 min), 10/90 (20 min), 95/5 (20.1 min), 95/5 (30 min). Mass spectrometry with an electrospray ionization source was used for metabolite identification. The heated capillary was maintained at $320{ }^{\circ} \mathrm{C}$. The spray voltage was set to $3.8 \mathrm{kV}$ in positive mode and $3.4 \mathrm{kV}$ in negative mode. The sheath and auxiliary gases were at 25 arbs and 8 arbs, respectively. $m / z 100$ to 1500 was scanned and the three most intense peaks were collided. The compounds were identified using the Compound Discoverer 2.1.0.401 database. Peak area of an identified compound was used for relative quantification. 


\section{Assay of cell invasion and cell migration ability}

To evaluate the effect of CFS from Lactobacillus on CRC cell invasion and migration, Transwell ${ }^{\mathrm{TM}}$ chamber assays (Corning Incorporated Costar, USA) were used. Briefly, $3 \times 10^{5}$ CRC cells were added into the upper chamber of each Transwell insert. For the analysis of cell invasion, the upper chambers had been coated with $200 \mu \mathrm{L}$ of Matrigel $(200 \mu \mathrm{g} / \mathrm{mL})$ diluted with serum-free DMEM (cell migration did not require the Matrigel coating). The lower chamber contained $600 \mu \mathrm{L}$ DMEM with $10 \%$ FBS (HT-29) or MEM with 20\% FBS (Caco2). Cells were allowed to invade for $24 \mathrm{~h}$. After that, the upper chamber was washed with phosphate-buffered saline (PBS) and carefully wiped with a cotton swab to remove excess PBS and residual cells from the upper chamber. Cells that had invaded through the Matrigel onto the bottom side of the Transwell insert were soaked in $95 \%$ ethanol and stained with crystal violet [42]. Finally, the image of the invaded cells was viewed using ToupView 3.7, and then quantified by the method of Escamilla [34]. The analysis was performed in triplicate.

\section{Analysis of gene expression}

The impact of Lactobacillus CFS on the expression of $M M P 2, M M P 9$, and VEGF in CRC cells was analysed using SYBR Green Real-Time PCR. Briefly, CRC cells were plated on a 6 well tissue culture plate and incubated for $4 \mathrm{~h}$ with $3 \mathrm{~mL}$ CFS from $24 \mathrm{~h}$ cultures of strains GG, M3, or YYC-3 (pH adjusted to 7.2 using $1 \mathrm{M} \mathrm{NaOH}$ ). Afterwards, cells were washed twice with PBS (pH 7.2). For cell harvest, $1 \mathrm{~mL}$ of PBS was added into each well and the wells were scraped with a cell scraper (Corning Incorporated Costar). Cells were collected into sterile $1.5 \mathrm{~mL}$ tubes, and centrifuged at $180 \times g$ for $2 \mathrm{~min}$. The tubes and cell pellets were immediately placed into liquid nitrogen for quick-freezing. RNA was extracted from each sample according to a previously described method [43]. The quality and quantity of the extracted RNA was evaluated using a NanoDrop ${ }^{\circledR}$ ND-2000 spectrophotometer (Thermos, USA) and 1.5\% modified agarose gel electrophoresis. For cDNA synthesis, PrimeScript ${ }^{\mathrm{TM}} \mathrm{RT}$ reagent kit with gDNA Eraser was used to synthesize cDNA from the mRNA, $20 \mu \mathrm{L}$ reverse transcription system contains $1 \mu \mathrm{g}$ RNA. Agarose gel electrophoresis was used to confirm the synthesis of cDNA. The relative gene expression was analysed by RT-PCR, using GAPDH as a reference gene (primers are listed in Table 2). According to the manufacturer's instructions, $2 \mu \mathrm{L}$ of cDNA was added into an $18 \mu \mathrm{L}$ reaction mixture containing $10 \mu \mathrm{M}$ primers and $2 \times$ Master Mix. An ABI 7500 instrument (Applied Biosystems, USA) was used to perform the RTPCR. The amplification reaction was set as $30 \mathrm{~s}$ at $95{ }^{\circ} \mathrm{C}$ for 40 cycles, followed by $10 \mathrm{~s}$ at $95{ }^{\circ} \mathrm{C}, 60{ }^{\circ} \mathrm{C}$ for $60 \mathrm{~s}$, $95^{\circ} \mathrm{C}$ for $15 \mathrm{~s}$, and then increasing the temperature from $60{ }^{\circ} \mathrm{C}$ to $99{ }^{\circ} \mathrm{C}$ to establish the melt curve of PCR products. Each sample was evaluated in triplicate. Data were analysed using the $2^{-\triangle \triangle \mathrm{CT}}$ method by ABI7500 SD2.3 software.

\section{Analysis of protein level}

The impact of Lactobacillus CFS on protein level of MMP2, MMP9, and VEGF was explored using western blot analysis. CRC cells were treated and collected according to the method described in section 'Analysis of gene expression'. After sample collection, cells were lysed for $20 \mathrm{~min}$ in RIPA buffer supplemented with $1 \mathrm{mM}$ PMSF and protease inhibitor cocktail tablet (Roche) on ice. Then the lysed cells were centrifuged at $1300 \times g$ for $20 \mathrm{~min}$ at $4{ }^{\circ} \mathrm{C}$, and the protein supernatants were collected. Moreover, the protein samples were homogenized by electric tissue homogenizer (TianGen BioTEC, OSE-Y30, China) with the speed of $1500 \times g$ for $10 \mathrm{~s}$, and then homogenizing three times at $10 \mathrm{~s}$ intervals. After homogenization, the samples were incubated on ice for $20 \mathrm{~min}$ and centrifuged at $4{ }^{\circ} \mathrm{C}, 1300 \times g$ for $20 \mathrm{~min}$, followed by collecting the supernatant. Furthermore, BCA protein assay kit (BioDee BioTech, China) was used to analyse the concentration of the protein and then the protein concentration was adjusted by RIPA, and the final concentration of the sample was $4 \mathrm{mg} / \mathrm{mL}$ after adding $5 \times$ reduction sample buffer. Protein supernatants were analysed by $12 \%$ sodium dodecyl sulphate-polyacrylamide gel electrophoresis (SDS-PAGE). Proteins were transferred onto nitrocellulose membranes (Millipore, USA) by a wet transfer method at $300 \mathrm{~mA}$ for $120 \mathrm{~min}$. After protein transfer, the membranes were blocked in 5\% skim milk-TBST, and then shaken gently at room temperature for $30 \mathrm{~min}$. Primary antibodies (rabbit anti-human IgG, obtained from Abcam, Cambridge, UK), including MMP2 (1:2000 dilution), MMP9 (1:2000), and VEGFA (1:2000) were added to the membranes, then retained for $10 \mathrm{~min}$ at room temperature, then at $4{ }^{\circ} \mathrm{C}$. After $24 \mathrm{~h}$, membranes were washed five times using TBST (3 min for each wash). Secondary antibody (goat anti-rabbit IgG, horseradish peroxidase-conjugated) obtained from TDY Biotech Co., Ltd., China was diluted 10,000 times with skim milk/TBST. Membranes were incubated with secondary antibody at room temperature for $40 \mathrm{~min}$ with gentle shaking. Electrochemical luminescence reagents were added to the membrane, reacted for 3-5 $\mathrm{min}$, and autoradiography film was exposed to the membrane for $10 \mathrm{~s}$ to $5 \mathrm{~min}$. Finally, the film was developed for $2 \mathrm{~min}$, and fixed. Protein band intensities were analysed using Image-J software and the housekeeping protein was $\beta$-actin. 


\section{Analysis of secretion level by ELISA kit} EliKine $^{\mathrm{TM}}$ Human MMP2 and MMP9 ELISA kit (Abbkine), and Human VEGFA ELISA kit (Abcam) were used to analyse the inhibitory ability of Lactobacillus CFSs on the secretion level of MMP2, MMP9, and VEGFA. In brief, $3 \times 10^{5}$ cells were cultured in six well plates, then samples were added and incubated for $24 \mathrm{~h}$. After that, the cell supernatants were collected from each group, and the contents of these proteins were analysed according to the manufacturer's instruction. In briefly, the specific antibody for MMP2 and MMP9 were coated on a 96 well plate. After reaction that the colour from blue to yellow in the wells, protein levels were measure using spectrophotometer (TECAN, Spark 20 M, Switzerland) and read at $450 \mathrm{~nm}$.

\section{Assessment of MMP-2 and MMP-9 activities using gelatine zymography}

MMP gelatine zymography electrophoresis analysis kit (Genmed Scientifics Inc, USA) was carried out to assess the inhibitory effect of CFSs on MMP2 and MMP9 activities. The sample was prepared as described by Escamilla et al. [34]. BCA protein assay kit (BioDee BioTech, China) was used to analyse the concentration of the protein. Then, extracellular MMP2 and MMP9 activities were tested according to the manufacturer's instruction. Proteins were separated by $10 \%$ polyacrylamide gels of SDSPAGE. Samples with loading buffer at 3:1 ratio for $20 \mu \mathrm{L}$ were added in each well, and running electrophoresis at $125 \mathrm{~V}$ for $1.5 \mathrm{~h}$. After that, the gel was washed in renaturation solution for $1 \mathrm{~h}$, followed by digestion for shaking at $37{ }^{\circ} \mathrm{C}$ for $24 \mathrm{~h}$. After staining and decolorization, using the termination solution to stop the reaction. Their activities were assessed by the quantification of the bands. The bands images were viewed using Clinx Genosens Capture program, and then quantified using ImageJ system.

\section{Statistical analysis}

All data in this experiment are expressed as mean \pm standard deviation of triplicate values. Data were analysed by Turkey test of One-way analysis of variance (ANOVA) in SPSS 19.0 software. P-value less than 0.05 was considered statistically significant.

\section{Supplementary information}

Supplementary information accompanies this paper at https://doi. org/10.1186/s12934-020-01466-2.

Additional file 1: Figure S1. The images of cell migration. All CFS treatments inhibited cell migration compared with negative controls at the concentration of $80 \mu \mathrm{L} / \mathrm{mL}$ (untreated group is the negative control and the 5-FU treatment group is the positive control).

\section{Acknowledgements}

We thank the native English-speaking scientists of Elixigen Company (Huntington Beach, California) for editing our manuscript.

\section{Authors' contributions}

Conceptualization, $Y-C Y$ and $X-X X$; Methodology, $Y-C Y, X-Y P$, and J-PL; Validation, Y-CY, B-YY; Formal Analysis, JL and S-WZ; Investigation, LL and KN; Writing-Review \& Editing, $Y$-CY and $X-X X$ All authors read and approved the final manuscript.

\section{Funding}

This work was supported by the National Key R\&D Program of China (2018YFD0400905), National Natural Science Foundation of China (31871833), and by the National Key R\&D Program of China (2017YFC1600903).

\section{Data availability}

The supplement data are availability from the corresponding author if required.

\section{Competing interests}

The authors declare no competing interests.

Received: 18 December 2019 Accepted: 29 October 2020

Published online: 23 November 2020

\section{References}

1. Patel AP, Fisher JL, Nichols E, Abd-Allah F, Abdela J, Abdelalim A, Abraha HN, Agius D, Alahdab F, Alam T, et al. Global, regional, and national burden of brain and other CNS cancer, 1990-2016: a systematic analysis for the Global Burden of Disease Study 2016. Lancet Neurol. 2019;18:376-93.

2. Torre LA, Bray F, Siegel RL, Ferlay J, Lortet-Tieulent J, Jemal A. Global cancer statistics, 2012. CA Cancer J Clin. 2015;65:87-108.

3. Wynendaele E, Verbeke F, D'Hondt M, Hendrix A, Van De Wiele C, Burvenich C, Peremans K, De Wever O, Bracke M, De Spiegeleer B. Crosstalk between the microbiome and cancer cells by quorum sensing peptides. Peptides. 2015;64:40-8.

4. Moschen AR, Gerner RR, Wang J, Klepsch V, Adolph TE, Reider SJ, Hackl H, Pfister A, Schilling J, Moser PL, et al. Lipocalin 2 protects from inflammation and tumorigenesis associated with gut microbiota alterations. Cell Host Microbe. 2016:19:455-69.

5. Sharifi S, Mohseni R, Amiri I, Tavilani H. Sperm matrix metalloproteinase-2 activity increased in pregnant couples treated with intrauterine insemination: a prospective case control study. J Obstet Gynaecol. 2019:39(5):675-80.

6. Sudhakaran S, Athira SS, Mohanan PV. Zinc oxide nanoparticle induced neurotoxic potential upon interaction with primary astrocytes. Neurotoxicology. 2019;73:213-27.

7. Yang Y, Weng W, Peng J, Hong L, Yang L, Toiyama Y, Gao R, Liu M, Yin M, Pan C, et al. Fusobacterium nucleatum increases proliferation of colorectal cancer cells and tumor development in mice by activating toll-like receptor 4 signaling to nuclear factor-kappaB, and up-regulating expression of MicroRNA-21. Gastroenterology. 2017;152(851-866):e824.

8. Gorkiewicz G, Moschen A. Gut microbiome: a new player in gastrointestinal disease. Virchows Arch. 2018;472:159-72.

9. Thirabunyanon M, Boonprasom P, Niamsup P. Probiotic potential of lactic acid bacteria isolated from fermented dairy milks on antiproliferation of colon cancer cells. Biotechnol Lett. 2009;31:571-6.

10. Swetwiwathana A, Visessanguan W. Potential of bacteriocin-producing lactic acid bacteria for safety improvements of traditional Thai fermented meat and human health. Meat Sci. 2015:109:101-5.

11. Yue Y, Xu X, Yang B, Lu J, Zhang S, Liu L, Nassar K, Zhang C, Zhang M, Pang $X$, Lv J. Stable colonization of orally administered Lactobacillus casei SY13 alters the gut microbiota. Biomed Res Int. 2020. https://doi. org/10.1155/2020/5281639.

12. Hill C, Guarner F, Reid G, Gibson GR, Merenstein DJ, Pot B, Morelli L, Canani RB, Flint HJ, Salminen S, et al. Expert consensus document. The International Scientific Association for Probiotics and Prebiotics consensus statement on the scope and appropriate use of the term probiotic. Nat Rev Gastroenterol Hepatol. 2014;11:506-14. 
13. Woraprayote W, Malila Y, Sorapukdee S, Swetwiwathana A, Benjakul S, Visessanguan W. Bacteriocins from lactic acid bacteria and their applications in meat and meat products. Meat Sci. 2016;120:118-32.

14. Tiptiri-Kourpeti A, Spyridopoulou K, Santarmaki V, Aindelis G, Tompoulidou E, Lamprianidou EE, Saxami G, Ypsilantis P, Lampri ES, Simopoulos C, et al. Lactobacillus casei exerts anti-proliferative effects accompanied by apoptotic cell death and up-regulation of TRAIL in colon carcinoma cells. PLOS ONE. 2016;11:e0147960.

15. Hasannejad Bibalan M, Eshaghi M, Rohani M, Esghaei M, DarbanSarokhalil D, Pourshafie MR, Talebi M. Isolates of Lactobacillus plantarum and $L$. reuteri display greater antiproliferative and antipathogenic activity than other Lactobacillus isolates. J Med Microbiol. 2017:66:1416-20.

16. Chondrou P, Karapetsas A, Kiousi DE, Tsela D, Tiptiri-Kourpeti A, Anestopoulos I, Kotsianidis I, Bezirtzoglou E, Pappa A, Galanis A. Lactobacillus paracasei $\mathrm{K} 5$ displays adhesion, anti-proliferative activity and apoptotic effects in human colon cancer cells. Benef Microbes. 2018;9(6):975-83.

17. Nowak A, Paliwoda A, Blasiak J. Anti-proliferative, pro-apoptotic and antioxidative activity of Lactobacillus and Bifidobacterium strains: a review of mechanisms and therapeutic perspectives. Crit Rev Food Sci Nutr. 2018. https://doi.org/10.1080/10408398.2018.1494539.

18. Ghanavati R, Asadollahi P, Shapourabadi MB, Razavi S, Talebi M, Rohani M. Inhibitory effects of Lactobacilli cocktail on HT-29 colon carcinoma cells growth and modulation of the Notch and Wnt/beta-catenin signaling pathways. Microb Pathog. 2020;139:103829.

19. Park JY, Park DH, Jeon Y, Kim YJ, Lee J, Shin MS, Kang KS, Hwang GS, Kim HY, Yamabe N. Eupatilin inhibits angiogenesis-mediated human hepatocellular metastasis by reducing MMP-2 and VEGF signaling. Bioorg Med Chem Lett. 2018;28:3150-4.

20. Munaut C, Noel A, Hougrand O, Foidart JM, Boniver J, Deprez M. Vascular endothelial growth factor expression correlates with matrix metalloproteinases MT1-MMP, MMP-2 and MMP-9 in human glioblastomas. Int J Cancer. 2003;106:848-55.

21. Poyer F, Coquerel B, Pegahi R, Cazin L, Norris V, Vannier JP, Lamacz M Secretion of MMP-2 and MMP-9 induced by VEGF autocrine loop correlates with clinical features in childhood acute lymphoblastic leukemia. Leuk Res. 2009;33:407-17.

22. Tilg H, Adolph TE, Gerner RR, Moschen AR. The intestinal microbiota in colorectal cancer. Cancer Cell. 2018;33:954-64.

23. Yue Y, Ye K, Lu J, Wang X, Zhang S, Liu L, Yang B, Nassar K, Xu X, Pang X, LV J. Probiotic strain Lactobacillus plantarum YYC-3 prevents colon cancer in mice by regulating the tumour microenvironment. Biomed Pharmacother 2020:127:110159.

24. Ahmadi S, Ghollasi M, Hosseini HM. The apoptotic impact of nisin as a potent bacteriocin on the colon cancer cells. Microb Pathog. 2017;111:193-7.

25. Joo NE, Ritchie K, Kamarajan P, Miao D, Kapila YL. Nisin, an apoptogenic bacteriocin and food preservative, attenuates HNSCC tumorigenesis via CHAC1. Cancer Med. 2012;1:295-305.

26. Oelschlaeger TA. Mechanisms of probiotic actions - a review. Int J Med Microbiol. 2010;300:57-62.

27. An BC, Hong S, Park HJ, Kim BK, Ahn JY, Ryu Y, An JH, Chung MJ. Anticolorectal cancer effects of probiotic-derived p8 protein. Genes (Basel). 2019:10(8):624

28. Lee JE, Lee J, Kim JH, Cho N, Lee SH, Park SB, Koh B, Kang D, Kim S, Yoo $\mathrm{HM}$. Characterization of the anti-cancer activity of the probiotic bacterium Lactobacillus fermentum using 2D vs. 3D culture in colorectal cancer cells. Biomolecules. 2019;9(10):557.

29. Del Carmen S, de Moreno de LeBlanc A, Levit R, Azevedo V, Langella P, Bermudez-Humaran LG, LeBlanc JG. Anti-cancer effect of lactic acid bacteria expressing antioxidant enzymes or IL-10 in a colorectal cancer mouse model. Int Immunopharmacol. 2017;42:122-9.

30. Faghfoori Z, Pourghassem Gargari B, Saber A, Seyyedi M, Fazelian S, Yari Khosroushahi A. Prophylactic effects of secretion metabolites of dairy lactobacilli through downregulation of ErbB-2 and ErbB-3 genes on colon cancer cells. Eur J Cancer Prev. 2017. https://doi.org/10.1097/CEJ.00000 00000000393.

31. Chen ZY, Hsieh YM, Huang CC, Tsai CC. Inhibitory effects of probiotic lactobacillus on the growth of human colonic carcinoma cell line HT-29. Molecules. 2017;22:107.

32. Vemuri $R$, Shinde $T$, Shastri MD, Perera AP, Tristram S, Martoni CJ, Gundamaraju R, Ahuja KDK, Ball M, Eri R. A human origin strain Lactobacillus acidophilus DDS-1 exhibits superior in vitro probiotic efficacy in comparison to plant or dairy origin probiotics. Int J Med Sci. 2018;15:840-8.

33. Zhang B, Li A, Zuo F, Yu R, Zeng Z, Ma H, Chen S. Recombinant Lactococcus lactis NZ9000 secretes a bioactive kisspeptin that inhibits proliferation and migration of human colon carcinoma HT-29 cells. Microb Cell Fact. 2016;15:102.

34. Escamilla J, Lane MA, Maitin V. Cell-free supernatants from probiotic Lactobacillus casei and Lactobacillus rhamnosus GG decrease colon cancer cell invasion in vitro. Nutr Cancer. 2012;64:871-8.

35. Kimura Y. Carp oil or oleic acid, but not linoleic acid or linolenic acid, inhibits tumor growth and metastasis in Lewis lung carcinoma-bearing mice. Nutr Cancer. 2002;132(7):2069-75.

36. Lee DH, Lee EH, Koh YJ, Cho CH, Lee J, Jeon J, Kim KJ, Yun JH, Jeong HS. Oleanolic acids inhibit vascular endothelial growth factor receptor 2 signaling in endothelial cells: implication for anti-angiogenic therapy. Mol Cells. 2018:8:771-80.

37. Prasad S, Gupta SC, Tyagi AK, Aggarwal BB. gamma-Tocotrienol suppresses growth and sensitises human colorectal tumours to capecitabine in a nude mouse xenograft model by down-regulating multiple molecules. Br J Cancer. 2016;115:814-24.

38. Watanabe K, Zhang X-Y, Kitagawa K, Yunoki T, Hayashi A. The effect of clonidine on VEGF expression in human retinal pigment epithelial cells (ARPE-19). Graefe's Arch Clin Exp Ophthalmol. 2008;247:207-13.

39. Ferrara N, Kim KJ, Li B, Houck K, Winer J. The vascular endothelial growth factor proteins: identification of biologically relevant regions by neutralizing monoclonal antibodies. Growth Fact. 1992;7:53-64.

40. Nouri Z, Karami F, Neyazi N, Modarressi MH, Karimi R, Khorramizadeh MR, Taheri B, Motevaseli E. Dual anti-metastatic and anti-proliferative activity assessment of two probiotics on HeLa and HT-29 cell lines. Cell J. 2016:18:127-34.

41. Norouzi Z, Salimi A, Halabian R, Fahimi H. Nisin, a potent bacteriocin and anti-bacterial peptide, attenuates expression of metastatic genes in colorectal cancer cell lines. Microb Pathog. 2018;123:183-9.

42. Liu A, Liu L, Lu H. LnCRNA XIST facilitates proliferation and epithelialmesenchymal transition of colorectal cancer cells through targeting miR486-5p and promoting neuropilin-2. J Cell Physiol. 2019;234:13747-61.

43. Yang L, Chen J, Liu Y, Zhang S, Li S, Ding W. Validation of reference genes for quantitative gene expression analysis in Ralstonia pseudosolanacearum CQPS-1 under environment stress. J Microbiol Methods. 2018;148:104-9.

\section{Publisher's Note}

Springer Nature remains neutral with regard to jurisdictional claims in published maps and institutional affiliations. 